OPEN ACCESS

Edited by:

Luis F. Callado,

University of the Basque Country

(UPV/EHU), Spain

Reviewed by:

Anna Maria Pittaluga,

Università di Genova, Italy

Bruno Pierre Guiard,

Université Fédérale de Toulouse,

France

*Correspondence:

Santina Chiechio chiechio@unict.it

Maria A. Sortino

msortino@unict.it

Specialty section:

This article was submitted to

Neuropharmacology,

a section of the journal

Frontiers in Pharmacology

Received: 18 July 2017 Accepted: 02 October 2017 Published: 20 October 2017

Citation:

Zammataro M, Merlo S, Barresi M,

Parenti C, Hu H, Sortino MA and Chiechio S (2017) Chronic Treatment

with Fluoxetine Induces

Sex-Dependent Analgesic Effects and Modulates HDAC2 and mG/u2

Expression in Female Mice.

Front. Pharmacol. 8:743.

doi: 10.3389/fphar.2017.00743

\section{Chronic Treatment with Fluoxetine Induces Sex-Dependent Analgesic Effects and Modulates HDAC2 and mGlu2 Expression in Female Mice}

\author{
Magda Zammataro', Sara Merlo², Massimo Barresi ${ }^{3}$, Carmela Parenti', Huijuan $\mathrm{Hu}^{4}$, \\ Maria A. Sortino ${ }^{2 *}$ and Santina Chiechio ${ }^{1 *}$ \\ ${ }^{1}$ Department of Drug Sciences, University of Catania, Catania, Italy, ${ }^{2}$ Department of Biomedical and Biotechnological \\ Sciences, University of Catania, Catania, Italy, ${ }^{3}$ Institut des Maladie Neurodégénératives, Bordeaux, France, ${ }^{4}$ Department of \\ Pharmacology and Physiology, Drexel University College of Medicine, Philadelphia, PA, United States
}

Gender and sex differences in pain recognition and drug responses have been reported in clinical trials and experimental models of pain. Among antidepressants, contradictory results have been observed in patients treated with selective serotonin reuptake inhibitors (SSRIs). This study evaluated sex differences in response to the SSRI fluoxetine after chronic administration in the mouse formalin test. Adult male and female CD1 mice were intraperitoneally injected with fluoxetine (10 mg/kg) for 21 days and subjected to pain assessment. Fluoxetine treatment reduced the second phase of the formalin test only in female mice without producing behavioral changes in males. We also observed that fluoxetine was able to specifically increase the expression of metabotropic glutamate receptor type-2 (mGlu2) in females. Also a reduced expression of the epigenetic modifying enzyme, histone deacetylase 2 (HDAC2), in dorsal root ganglia (DRG) and dorsal horn $(\mathrm{DH})$ together with an increase histone 3 acetylation $(\mathrm{H} 3)$ level was observed in females but not in males. With this study we provide evidence that fluoxetine induces sex specific changes in HDAC2 and mGlu2 expression in the DH of the spinal cord and in DRGs and suggests a molecular explanation for the analgesic effects in female mice.

Keywords: pain, fluoxetine, sex differences, metabotropic glutamate 2 receptor, HDAC2

\section{INTRODUCTION}

In recent years gender and sex differences in pain recognition and drug responses have been extensively investigated both in clinical trials and experimental models of pain. Despite a large number of epidemiological studies clearly reveal that women report pain more frequently than men (Unruh, 1996; Berkley, 1997; Riley et al., 1998; Fillingim et al., 2009), results obtained in rodents are not always consistent and often depend on the type of pain and treatment protocol (Craft, 2003; Mogil et al., 2003). More recently, it has been demonstrated that the immune system differently mediates pain hypersensitivity in male and female rodents (Sorge et al., 2015) thus emphasizing the need to elucidate mechanisms underlying sex differences in pain responses with the aim to support the development of gender-specific drug therapies. 
Different classes of antidepressant drugs are clinically effective in various forms of chronic pain including arthritis, diabetic neuropathy, post-herpetic neuralgia, migraine, fibromyalgia, low back pain (Gilron et al., 2013). Antidepressant drugs act by blocking the norepinephine and/or serotonin transporter on presynaptic site enhancing the descending inhibitory control on pain (Millan, 2002; Berton and Nestler, 2006; Mika et al., 2013). Nevertheless, many other mechanisms can account for their analgesic activity involving sodium and calcium channels or a number of receptors including $\mathrm{GABAB}$, opioid, and adenosine receptors (Dharmshaktu et al., 2012). In this regard the activity as sodium and calcium blockers as well as the ability to decrease prostaglandin E2 production elicited by several antidepressants including fluoxetine, has been proposed as an important mechanism to explain the efficacy of antidepressants as analgesics (Dharmshaktu et al., 2012).

In clinical practice, it is generally accepted that the tricyclic antidepressant (TCA), amitriptyline, and the serotonin/noreprinephine reuptake inhibitor (SNRI), duloxetine, are effective in persistent pain (Attal et al., 2006; Finnerup et al., 2015). However, there is less agreement about the efficacy of antidepressants belonging to the selective serotonin reuptake inhibitor (SSRI) class (Sindrup et al., 2005; Saarto and Wiffen, 2007; Finnerup et al., 2010). Only few studies have demonstrated some efficacy of SSRIs such as paroxetine and citalopram but not fluoxetine in painful diabetic neuropathy (Sindrup et al., 1990, 1992; Max et al., 1992). On the other hand, in a number of trials that included almost exclusively women, the SSRI fluoxetine, has been shown to be effective in chronic tension-type headache (Walker et al., 1998) and in the treatment of fibromyalgia (Cantini et al., 1994; Wolfe et al., 1994; Goldenberg et al., 1996; Arnold et al., 2002), a musculoskeletal condition characterized by chronic widespread pain and muscle tenderness with a high prevalence on women compared to men (Wolfe et al., 1995).

In rodents the analgesic activity of antidepressant drugs has been evaluated both in models of acute and persistent pain. Most of the studies have been performed with high dose of antidepressants acutely injected (Bomholt et al., 2005; Obata et al., 2005). We have previously shown that fluoxetine is also effective in the formalin test after a single intraperitoneal injection and that the analgesic activity is lost in $L m \times 1 b$ conditional knock-out mice $\left(\operatorname{Lm} \times 1 b^{\mathrm{f} / \mathrm{f} / P}\right)$, which lack 5-HT neurons in the central nervous system (Zhao et al., 2007). However, protocols of acute treatment do not reproduce the clinical use of these drugs.

Based on these pieces of evidence, we sought to investigate whether a long-term administration with fluoxetine might have sex-specific effects in pain behavior in mice. Moreover, antidepressant treatment may induce direct epigenetic effects and fluoxetine itself is known to modulate the expression of epigenetic modifying enzymes (Perisic et al., 2010; Menke et al., 2012; Zimmermann et al., 2012; Menke and Binder, 2014; Erburu et al., 2015; Vierci et al., 2016).

Epigenetic modifications, including DNA methylation and changes of chromatin structure and function, are the most common mechanisms that control gene expression and, eventually, influence protein expression levels. DNA methylation involves direct chemical modification to the DNA, through the addition of a methyl group at the $5^{\prime}$ position of cytosines in $\mathrm{CpG}$ dinucleotides, and usually mediate repression of gene transcription (Newell-Price et al., 2000). On the other hand, a number of post-translational modifications of chromatin structure, including acetylation, methylation, phosphorylation may either increase and repress gene expression (Borrelli et al., 2008). In particular, acetylation is regulated by two classes of enzymes, histone acetyltransferases (HATs) and deacetylases (HDACs) that, respectively, promote acetylation and deacetylation of lysine tails in histone proteins (Mai et al., 2005).

We have first demonstrated that HDAC inhibitors produce analgesic effects via the upregulation of metabotropic glutamate receptor type-2 (mGlu2), an inhibitory receptor whose activation mediates analgesic effects in different pain models (Chiechio et al., 2009). Different HDAC proteins have been identified and subdivided in four classes (I, II, III, and IV) according to their structure, cellular localization and function (Sharma et al., 2013). Class I includes HDAC1, HDAC2, HDAC3, and HDAC8. Class II consists of six HDAC proteins that include HDAC4, HDAC5, HDAC6 HDAC7, HDAC9 and HDAC10, while HDAC11 belongs to class IV. Differently to the other HDAC proteins, class III HDACs operate by a $\mathrm{NAD}^{+}$-dependent mechanism and are referred to as sirtuins (SIRT1-7) (Grozinger and Schreiber, 2002). However, among HADACs, the HDAC2 is the only isoform that has been shown to regulate the expression of mGlu2 receptors (Kurita et al., 2012) and fluoxetine itself is known to modulate the expression of HDAC2 (Faillace et al., 2015).

With this in mind, we tested whether a chronic treatment with fluoxetine induces sex specific analgesic effects in the mouse formalin test. We also and evaluated HDAC2 and mGlu2 receptor expression in DRG and dorsal horn by western blot and immunohistochemistry analysis.

\section{RESULTS}

\section{Chronic Treatment with Fluoxetine Reduces the Second Phase of the Formalin Test in Female Mice}

Fluoxetine $(10 \mathrm{mg} / \mathrm{Kg})$ was intraperitoneally injected in adult male and female littermates for 21 days and pain behavior was evaluated in the mouse formalin test. The intraplantar (i.pl.) injection of a dilute solution of formalin (10 $\mu \mathrm{l}, 5 \%)$ induces a biphasic response, namely phase I and phase II, characterized by the flinching, lifting, and licking of the injected paw. The first phase starts immediately after the formalin injection and lasts about $10 \mathrm{~min}$. This phase represents an acute form of pain response deriving from the direct activation of nociceptors. Conversely, the second phase that starts after $10 \mathrm{~min}$ from the formalin injection, represents a tonic form of pain deriving from the establishment of an inflammatory response sustained by mechanisms of central sensitization in the dorsal horn of the spinal cord (Coderre and Melzack, 1992; Tjølsen et al., 1992). As reported in Figure 1, there was no statistical 

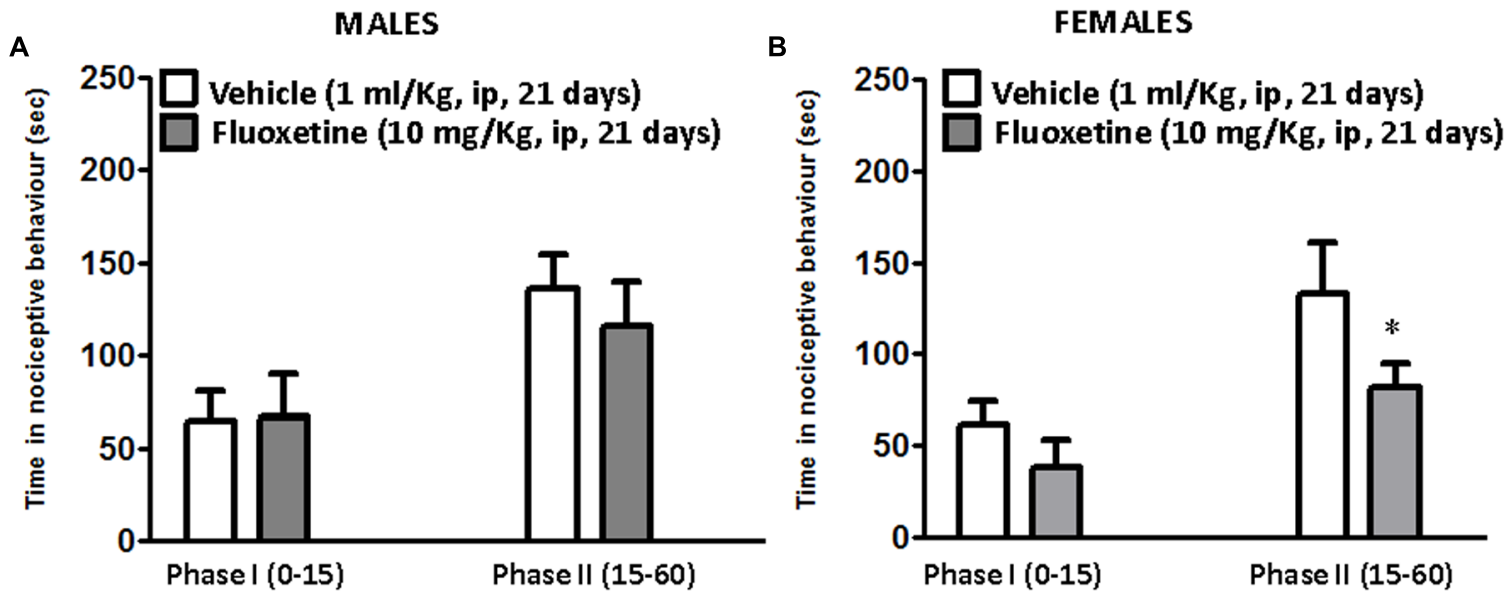

FIGURE 1 | Effects of chronic administration with fluoxetine in the formalin test in male and female CD1 mice. Chronic administration with fluoxetine (10 mg/Kg, i.p. for 21 days) fails to induce analgesia in male mice (A) but reduces the second phase of the formalin test in female CD1 mice (B). Data are means \pm SEM of 9 to 12 mice per sex/group. ${ }^{*} p<0.05$ versus the respective vehicle group (two tailed Student's $t$-test).

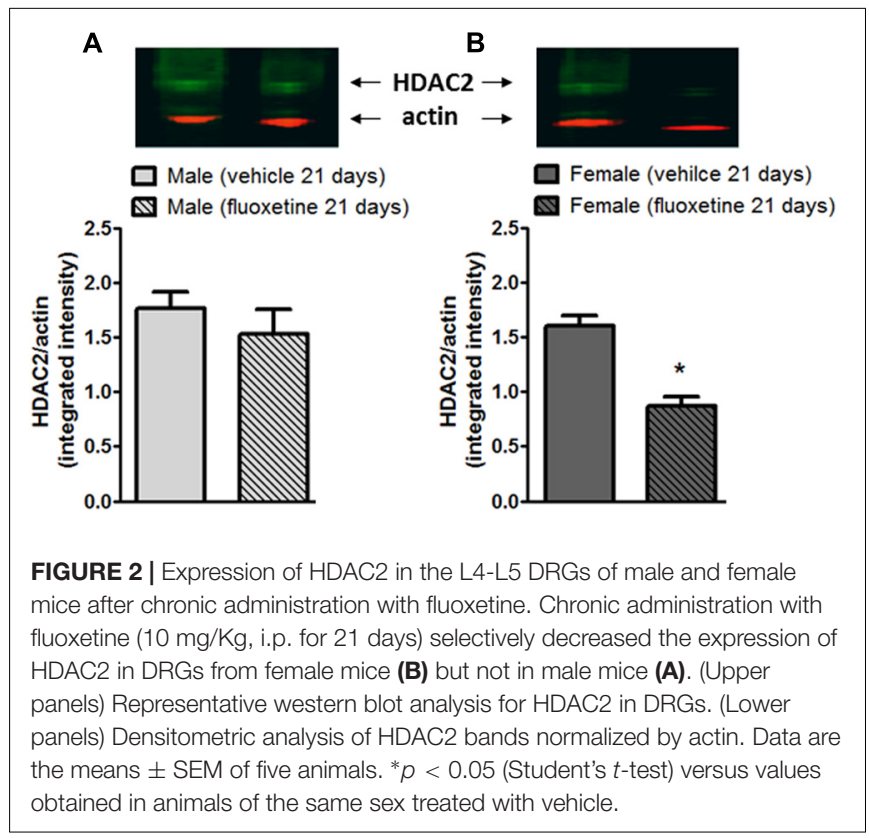

difference in the formalin test between vehicle treated male and female mice (Figures 1A,B). However, while repeated fluoxetine administration did not affect formalin behavior in male mice (Figure 1A) in both phases, the second phase of the formalin test was significantly reduced in female mice (Figure 1B), suggesting a sex-dependent analgesic effect of chronic fluoxetine.

\section{Chronic Treatment with Fluoxetine Reduces the Expression of HDAC2 in DRG of Female Mice}

Fluoxetine is known to induce direct epigenetic modification including increased levels of acetylated histone $\mathrm{H} 3$ and $\mathrm{H} 4$ proteins (Vierci et al., 2016). Moreover, HDAC2 levels have been shown to be reduced after chronic fluoxetine in the brain (Faillace et al., 2015). Thus, we investigated whether HDAC2 levels are modified in the DRG after a chronic treatment with fluoxetine in male and female mice. After a 21-day treatment with fluoxetine (10 mg/kg, i.p.), L4-L6 DRGs were removed and processed for protein analysis. As reported in Figure 2, western blot analysis shows that levels of HDAC2 were significantly decreased only in female mice (Figure 2B) whereas no changes were observed in male mice (Figure 2A) indicating that chronic fluoxetine is able to reduce the expression of HDAC2 in a sex-specific manner.

\section{Effects of Chronic Treatment with Fluoxetine on HDAC2 and mGlu2 Receptor Expression in the Spinal DH of Male and Female Mice}

By removing acetyl groups from histone proteins, HDACs promote an inactive state of chromatin resulting in the silencing of downstream genes. In particular, HDAC2 has been associated with a suppression on GRM2 gene encoding for the mGlu2 receptor (Kurita et al., 2012).

We combined immunohistochemistry and western blot analyses in order to evaluate whether HDAC2 expression is affected in the spinal dorsal horn of male and female mice after a 21-day treatment with fluoxetine $(10 \mathrm{mg} / \mathrm{kg}$, i.p.). Also, since the expression of mGlu2 receptor has been reported to be under the control of HDAC2 (Kurita et al., 2012), we tested whether mGlu2 receptor expression is affected by chronic treatment with fluoxetine.

As reported in Figure 3, no changes in HDAC2 expression were observed in male mice treated with fluoxetine (Figures 3A,B). Also no changes were detected in mGlu2 receptor expression in male mice (Figure 3C). Strikingly, a decrease in HDAC2 expression together with an increase in the expression of mGlu2 receptors was observed in female mice 


\section{A}

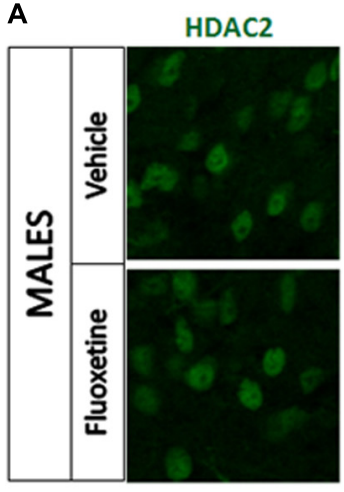

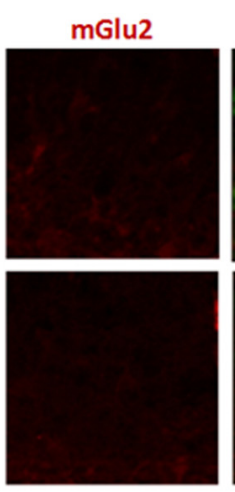
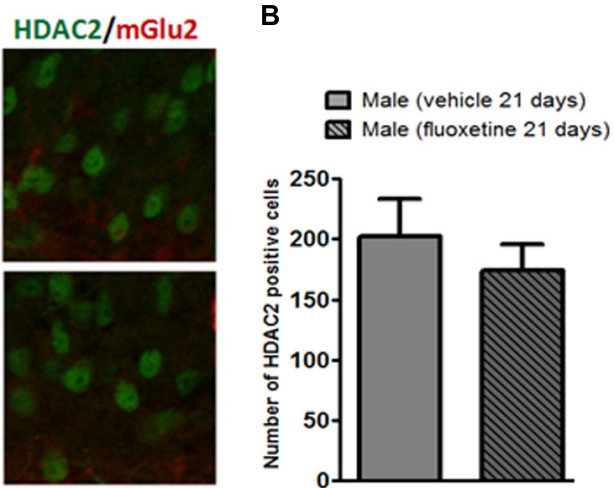

D

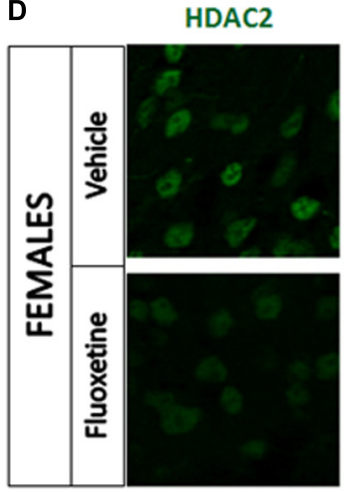

mGlu2

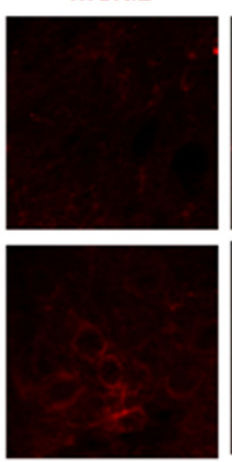

HDAC2/mGlu2

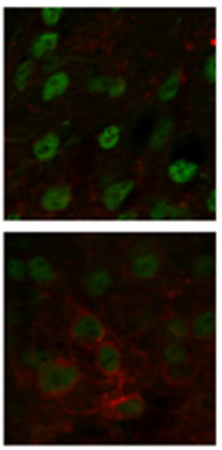

E

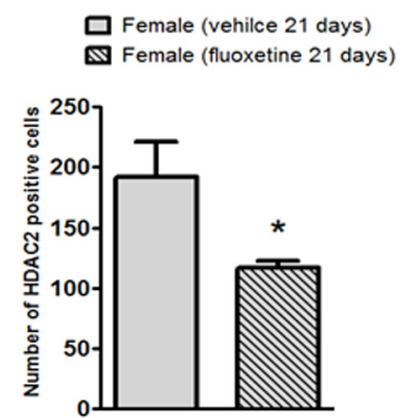

C

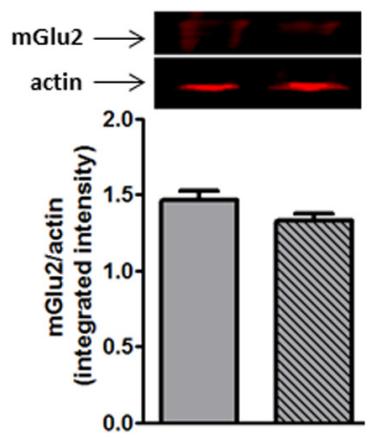

$\mathbf{F}$

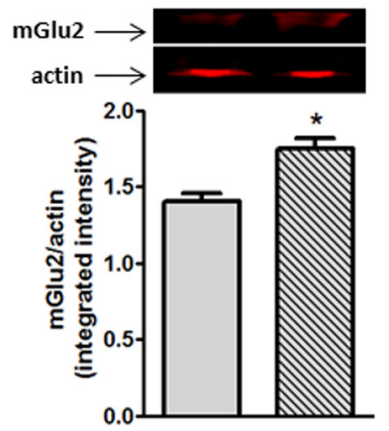

FIGURE 3 | Expression of HDAC2 and mGlu2 receptors in the lumbar dorsal horn of male and female mice after chronic administration with fluoxetine. (A,D) Representative examples of HADC2 positive cells (left column) and mGlu2 immunostaining (central column) or overlapping (right column) in the dorsal horn of the spinal cord in male and female mice after chronic treatment with fluoxetine. (B,E) Quantification of the cell density (cell number/area) for HDAC2 immunopositive cells. Bars represent average \pm SEM. * $p<0.05$ (Student's $t$-test) versus vehicle. (C,F) Densitometric analysis of mGlu2 bands normalized by actin. Data are the means \pm SEM of five animals. ${ }^{*} p<0.05$ (Student's $t$-test) versus values obtained in animals of the same sex treated with vehicle.

chronically treated with fluoxetine compared to vehicle treated female mice (Figures 3A-C).

\section{Effects of Chronic Treatment with Fluoxetine on Acetyl-Histone 3 Levels in the Spinal DH of Male and Female Mice}

Since HDACs remove acetyl groups from histone proteins, we investigated whether the downregulation of HDAC2 affected levels of acetyl- $\mathrm{H} 3$ in the dorsal horn of the spinal cord. As expected, immunohistochemisty analysis in the spinal DH shows that chronic fluoxetine increases levels of acetyl-H3 specifically in female mice (Figures 4C,D) whereas no changes were observed in male mice (Figures $4 \mathbf{A}, \mathbf{B}$ ). This result is consistent with the reduced expression of HDAC2 in female mice (Figures 3D,E).

\section{DISCUSSION}

Several studies have shown gender differences in antidepressant efficacy (Kokras and Dalla, 2017) and a number of clinical studies have reported that depressed women respond to SSRIs therapy better than males (Haykal and Akiskal, 1999; Kornstein et al., 2000; Quitkin et al., 2002; Berlanga and Flores-Ramos, 2006). Although hormonal and pharmacokintec differences have been postulated as likely candidates to explain different responses to antidepressant pharmacotherapy between sex, the underlying mechanisms are still unknown (Sramek et al., 2016).

Differences in pain sensitivity are also seen in women that usually report greater pain than men (Unruh, 1996; Berkley, 1997; Riley et al., 1998; Fillingim et al., 2009) and antidepressants are effective in relieving chronic pain (Gilron et al., 2013). However, little is known about sex differences in response to chronic antidepressant treatment for the management of chronic pain. Moreover, although it is believed that depression can exacerbate pain, there is evidence that the antidepressant and the analgesic effects occur independently. Antidepressants are analgesic in patients with chronic pain and no concomitant depression (Saarto and Wiffen, 2005, 2007). In addition, the delay of action of antidepressants in chronic pain management in some studies is shorter than in depression (Arnold et al., 2005). 
A
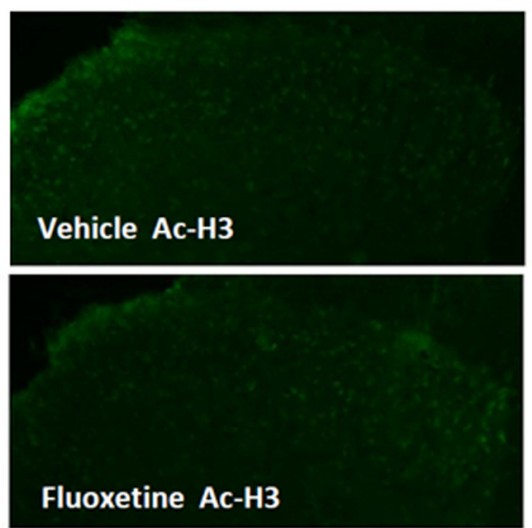

C

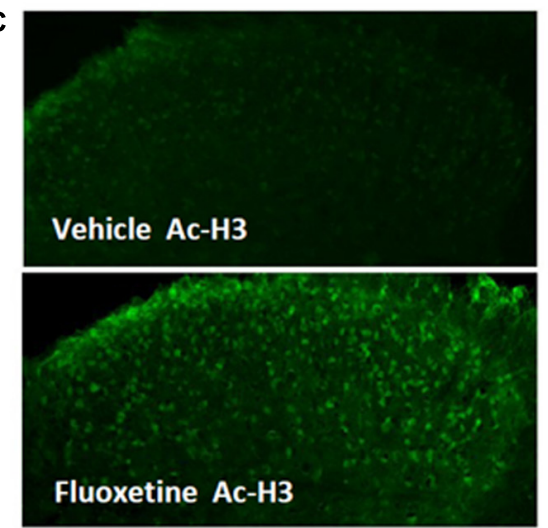

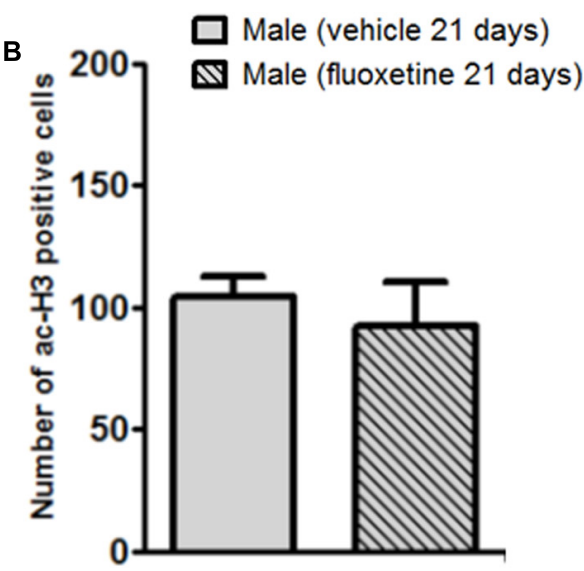

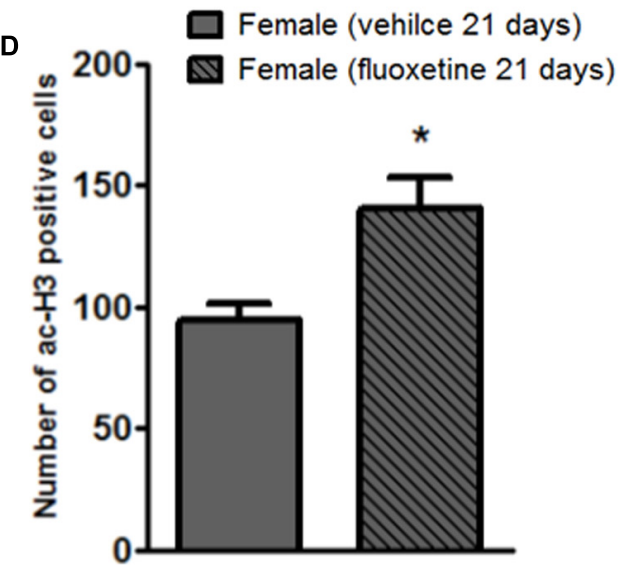

FIGURE 4 | Modulation of acetyl-H3 positive cell density in the dorsal horn of male and female mice by chronic treatment with fluoxetine. (A,C) Representative examples of acetyl-H3 immunopositive cells in the mouse dorsal horn from male and female mice treated with vehicle or fluoxetine (10 mg/kg, i.p.) for 21 days. (B,D) Quantification of immunopositive cells. Bars represent average \pm SEM of three animals. ${ }^{*} p<0.01$ (Student's $t$-test) versus values obtained in animals of the same sex treated with vehicle.

This work shows for the first time that chronic administration of fluoxetine induces sex-dependend analgesic effects in mice. We also observed sex-specific changes in mGlu2 expression in the $\mathrm{DH}$ and DRGs of female mice together with a decreased expression of HDAC2.

Metabotropic glutamate receptors are known to modulate pain sensitivity (Chiechio and Nicoletti, 2012; Palazzo et al., 2014; Chiechio, 2016). In particular analgesia can be obtained by either blocking group I mGlu receptors, namely mGlul and mGlu5 (Walker et al., 2001; Sasikumar et al., 2010; Bennett et al., 2012; Brumfield et al., 2012) or by activating group II and group III mGlu receptors (Chiechio and Nicoletti, 2012; Chiechio, 2016; Johnson et al., 2017). Also, we have demonstrated that epigenetic drugs that increase the expression of $\mathrm{mGlu} 2$ receptors are analgesic in models of persistent pain (Chiechio et al., 2002, 2009, 2010; Zammataro et al., 2014).

Antidepressant drugs are known to induce analgesic effects. Different mechanisms have been demonstrated to explain their efficacy in reducing pain. However, long term regulation of gene expression and epigenetic mechanisms are likely to occur after chronic administration. In this regard, it is important to mention that different classes of antidepressant drugs have been demonstrated to have a plethora of effects in CNS disorders and are also known to have a role in neurogenesis (Wang et al., 2011; Masuda et al., 2012; Meneghini et al., 2014; Zhou et al., 2016; King et al., 2017). Many of these effects are sex-dependent (Gray and Hughes, 2015; Kokras and Dalla, 2017) and fluoxetine itself is known to induce sex specific effects on neurogenesis (Hodes et al., 2010). However, so far, no studies have investigated whether longterm treatment with antidepressant drugs affect pain behavior in a sex-dependent manner.

With this study we have shown that chronically administered fluoxetine induces sex-specific analgesic effects in the mouse formalin test and modulates the expression of the epigenetic modifying enzymes, HDAC2, and the expression of mGlu2 receptors in the spinal dorsal horn and DRG of female mice.

A number of HDAC inhibitors have been tested in different pain models and it has been shown that they have analgesic effects 
through different mechanisms (Chiechio et al., 2009, 2010; Bai et al., 2010; Zhang et al., 2011; Denk et al., 2013; Matsushita et al., 2013; Onofrj et al., 2013; Ximenes et al., 2013; Chen et al., 2014; Kukkar et al., 2014; Zammataro et al., 2014; Capasso et al., 2015; Cao et al., 2016; Tao et al., 2016; Alqinyah et al., 2017; Fork et al., 2017; Lin et al., 2017). We first demonstrated that HDAC inhibitors have analgesic properties via the upregulation of the metabotropic glutamate receptor type-2 (Chiechio et al., 2009, 2010; Onofrj et al., 2013), an inhibitory receptor whose activation or upregulation mediates analgesia (Chiechio et al., 2002, 2009, 2010; Onofrj et al., 2013; Zammataro et al., 2014; Chiechio, 2016). More recently, the isoform HDAC2 has been involved both in pain modulation (Kim et al., 2011; Zhao et al., 2011; Yang et al., 2015; Maiarù et al., 2016) and in the regulation of mGlu2 promoter activity (Kurita et al., 2012) and fluoxetine itself has been reported to regulate the expression of the HDAC2 isoform (Faillace et al., 2015).

In our experimental protocol we did not find sex differences in the formalin test in saline treated mice. Previous studies have reported sex differences in the mouse formalin test only in a late phase, phase 3, developing after $1 \mathrm{~h}$ of formalin injection, but not in phases 1 and 2 as observed in the present study (Kim et al., 1999). However, in pain studies phase 3 is rarely measured as it is considered less reproducible and relevant than phases 1 and 2 that reflect acute and tonic phase of pain, respectively (Coderre and Melzack, 1992; Tjølsen et al., 1992). Consistent with our findings, the lack of analgesic effect of chronically injected fluoxetine in male mice has been previously reported in a persistent pain model such as the sciatic nerve cuffing in mice, where, similarly to clinical observations, TCAs such as amitriptyline and nortriptyline were able to elicit analgesic effects while fluoxetine resulted ineffective (Benbouzid et al., 2008). Hormonal and genetic factors might influence pain sensitivity and the response to specific pharmacological treatments. Also, pharmacokinetic differences may account for the analgesic effects of fluoxetine in female mice. Female mice are known to metabolize fluoxetine and to produce more norfluoxetine than males in the brain (Hodes et al., 2010). On the other hand norfluoxetine has been shown to interact with estrogen receptors to regulate ER-mediated gene expression (Lupu et al., 2015). Furthermore, estradiol is able to reduce the expression of HDAC2 in the hippocampus (Zhao et al., 2010).

\section{CONCLUSION}

In summary, this study provides evidence that antidepressant drugs might have sex-specific analgesic effects after chronic administration. The observation that fluoxetine induces sex specific changes in HDAC2 and mGlu2 expression in the dorsal horn of the spinal cord and in DRGs provides a molecular explanation for the analgesic effects in females and suggests that estrogens and/or estrogen receptors might play a role in the observed effects. Studies in ovariectomized female mice and estrogen replacement protocols are in progress to investigate mechanisms underlying the observed differences in male and female mice in response to a chronic treatment with fluoxetine.
So far we hypothesize that fluoxetine induces analgesic effects in female mice by reducing the expression of HDAC2 and consequently upregulating the $\mathrm{mGlu} 2$ receptor, known to induce analgesia.

\section{MATERIALS AND METHODS}

\section{Animals}

Male and female CD1 mice littermates aged between 8 and 12 weeks were used for these experiments. All experiments were done in accordance with experimental protocols approved by the animal study committee at University of Catania, Italy (IACUC project 161/2012).

\section{Drugs}

The dose of fluoxetine was chosen according to previous studies (Singh et al., 2001; Iyengar et al., 2004; Jones et al., 2005; Zhao et al., 2007). In addition, we performed preliminary studies to identify a dose that produced analgesic effects without causing toxicity or motor impairment. To evaluate the effects of chronic administration of fluoxetine $(10 \mathrm{mg} / \mathrm{kg}$; Tocris) on acute and persistent pain, mice were randomly assigned to different groups by an independent researcher and intraperitoneally injected with vehicle (saline, $1 \mathrm{ml} / \mathrm{kg}$ ) or fluoxetine $(10 \mathrm{mg} / \mathrm{kg}$ ) for 21 consecutive days.

\section{Behavioral Experiments}

Littermate male and female mice aged between 8 and 9 weeks were acclimated to the experimental room and were used for behavioral tests by observers blind to the sex and the treatment of the animals.

\section{Formalin Test}

Formalin (5\%, $10 \mu \mathrm{l}$; Sigma-Aldrich) was injected subcutaneously into the plantar surface of the right hind paw, and the total time spent licking and flinching the injected paw was monitored for $1 \mathrm{~h}$ and recorded every $5 \mathrm{~min}$ as reported previously (Chiechio et al., 2009). Formalin scores were separated into two phases, phase I (0-10 $\mathrm{min})$ and phase II (15-50 min). A mean response was then calculated for each phase. All tests were performed and analyzed blind to treatment.

\section{Immunohystochemical Staining}

After the behavioral test mice were euthanized by $\mathrm{CO}_{2}$ inhalation and spinal cord was removed and kept in $4 \%$ paraformaldehyde at $4^{\circ} \mathrm{C}$ overnight and then in $30 \%$ sucrose for cryoprotection. Sections $(20 \mu \mathrm{m}$ thick) from the lumbar segment were sequentially collected using a sliding microtome and stored at $-20^{\circ} \mathrm{C}$ in an anti freezer solution containing $30 \%$ ethylene glycol in $0.1 \mathrm{M}$ phosphate buffer (PBS). For immunohystochemical staining, spinal cord sections from the lumbar segment were sequentially incubated with rabbit anti-HDAC2 (1:200, Abcam) and mouse anti-mGlu2 (1:250 Abcam) in PBS containing 3\% bovine serum albumin (BSA, Sigma) and 0.1\% Triton X-100 overnight. The following fluorescent secondary antibodies were 
used: donkey anti-rabbit (1:200; Jackson Immuno Research) for $2 \mathrm{~h}$, and Cy3-conjugated streptavidin (1:1000; Jackson Immuno Research) for $1 \mathrm{~h}$. After washing with PBS, sections were coverslipped with a mounting medium for fluorescence (Sigma). Fluorescent signal was detected using a Zeiss Axio Observer.Z1 microscope equipped with the Apotome. 2 acquisition system (Carl Zeiss S.p.A, Milan, Italy).

Quantification and colocalization of positive cells in the dorsal horn were performed by an investigator blind to the treatment using Image-J software. At least three fields per slices from five slices per animals were analyzed. Three different mice/group were used. Statistical analysis was performed by using Student's $t$-test comparing treatment versus vehicle in animals of the same sex.

\section{Western Blot}

Mice were euthanized by $\mathrm{CO}_{2}$ inhalation and L5-L6 dorsal root ganglia and the lumbar segment of the spinal cord of male and female CD1 mice were removed and homogenized. Ten micrograms of total protein were separated by $10 \%$ SDSPAGE and electrophoretically transferred onto protein-sensitive PVDF transfer membranes (Thermo Scientific). Membranes were blocked in Odyssey blocker (LI-COR) for $1 \mathrm{~h}$ at room temperature and rabbit anti-HDAC2 (1:1000, Abcam), mouse anti-mGlu2 (1:1000, Abcam) or mouse anti-actin (1:1000, Sigma-Aldrich) primary antibody were simultaneously used for immunoblotting overnight at $4^{\circ} \mathrm{C}$. A goat anti-rabbit antibody labeled with IRD800CW and a goat anti-mouse antibody labeled with Alexa 680 (LICOR) were incubated for $1 \mathrm{~h}$ at room temperature. Proteins were detected with the Odyssey Infrared Fluorescence Imaging System (LI-COR) and protein quantification was expressed as integrated intensity.

\section{REFERENCES}

Alqinyah, M., Maganti, N., Ali, M. W., Yadav, R., Gao, M., Cacan, E., et al. (2017). Regulator of G protein signaling 10 (Rgs10) expression is transcriptionally silenced in activated microglia by histone deacetylase activity. Mol. Pharmacol. 91, 197-207. doi: 10.1124/mol.116.106963

Arnold, L. M., Hess, E. V., Hudson, J. I., Welge, J. A., Berno, S. E., and Keck, P. E. Jr. (2002). A randomized, placebo-controlled, double-blind, flexible-dose study of fluoxetine in the treatment of women with fibromyalgia. Am. J. Med. 112, 191-197. doi: 10.1016/S0002-9343(01)01089-0

Arnold, L. M., Rosen, A., Pritchett, Y. L., D’Souza, D. N., Goldstein, D. J., Iyengar, S., et al. (2005). A randomized, double-blind, placebo-controlled trial of duloxetine in the treatment of women with fibromyalgia with or without major depressive disorder. Pain 119, 5-15. doi: 10.1016/j.pain.2005.06.031

Attal, N., Cruccu, G., Haanpää, M., Hansson, P., Jensen, T. S., Nurmikko, T., et al. (2006). EFNS Task Force. EFNS guidelines on pharmacological treatment of neuropathic pain. Eur. J. Neurol. 13, 1153-1169. doi: 10.1111/j.1468-1331.2006. 01511.x

Bai, G., Wei, D., Zou, S., Ren, K., and Dubner, R. (2010). Inhibition of class II histone deacetylases in the spinal cord attenuates inflammatory hyperalgesia. Mol. Pain 6:51. doi: 10.1186/1744-8069-6-51

Benbouzid, M., Choucair-Jaafar, N., Yalcin, I., Waltisperger, E., Muller, A., FreundMercier, M. J., et al. (2008). Chronic, but not acute, tricyclic antidepressant treatment alleviates neuropathic allodynia after sciatic nerve cuffing in mice. Eur. J. Pain 12, 1008-1017. doi: 10.1016/j.ejpain.2008.01.010

Bennett, C. E., Burnett, D. A., Greenlee, W. J., Knutson, C. E., Korakas, P., $\mathrm{Li}$, C., et al. (2012). Fused tricyclic mGluR1 antagonists for the treatment of

\section{Statistical Analysis}

Sample size was calculated with the GPower software. A priori analysis was performed by $F$-test (ANOVA) with the following input parameters: alpha $=0.05$, power 1-beta $=0.95, F=0,40$ resulting in a total sample size of 56 mice. Behavioral data are presented as mean \pm SEM of at least nine animals per group. Statistical comparisons were performed with Student's $t$-test using the statistical software package GraphPad Prism. Western blot and immunochemical analyses are presented as mean \pm SEM of at least three independent experiments performed in triplicate. Statistical significance was determined using unpaired $t$-tests. In all cases, $p<0.05$ was considered statistically significant.

\section{ETHICS STATEMENT}

All experiments were approved by the local animal ethics committee.

\section{AUTHOR CONTRIBUTIONS}

The study was conceived by MZ and SC. Behavioral experiments were designed by MZ, HH, CP, and SC. Immunohistochemistry and western blot experiments were designed by SM, MB, MS, and SC. All authors contributed to writing the manuscript, and all read and approved the final manuscript.

\section{ACKNOWLEDGMENT}

This study was supported by an intramural grant from the University of Catania (PRA2008) (FIR 2014).

neuropathic pain. Bioorg. Med. Chem. Lett. 22, 1575-1578. doi: 10.1016/j.bmcl. 2011.12.131

Berkley, K. J. (1997). Sex differences in pain. Behav. Brain Sci. 20, 371-380. doi: 10.1017/S0140525X97221485

Berlanga, C., and Flores-Ramos, M. (2006). Different gender response to serotonergic and noradrenergic antidepressants. A comparative study of the efficacy of citalopram and reboxetine. J. Affect. Disord. 95, 119-123. doi: 10.1016/j.jad.2006.04.029

Berton, O., and Nestler, E. J. (2006). New approaches to antidepressant drug discovery: beyond monoamines. Nat. Rev. Neurosci. 7, 137-151. doi: 10.1038/ nrn 1846

Bomholt, S. F., Mikkelsen, J. D., and Blackburn-Munro, G. (2005). Antinociceptive effects of the antidepressants amitriptyline, duloxetine, mirtazapine and citalopram in animal models of acute, persistent and neuropathic pain. Neuropharmacology 48, 252-263. doi: 10.1016/j.neuropharm.2004.09.012

Borrelli, E., Nestler, E. J., Allis, C. D., and Sassone-Corsi, P. (2008). Decoding the epigenetic language of neuronal plasticity. Neuron 60, 961-974. doi: 10.1016/j. neuron.2008.10.012

Brumfield, S., Korakas, P., Silverman, L. S., Tulshian, D., Matasi, J. J., Qiang, L., et al. (2012). Synthesis and SAR development of novel mGluR1 antagonists for the treatment of chronic pain. Bioorg. Med. Chem. Lett. 22, 7223-7226. doi: 10.1016/j.bmcl.2012.09.048

Cantini, F., Bellandi, F., Niccoli, L., and Di Munno, O. (1994). Fluoxetin combined with cyclobenzaprine in the treatment of fibromyalgia. Minerva Med. 85, 97-100.

Cao, D. Y., Bai, G., Ji, Y., Karpowicz, J. M., and Traub, R. J. (2016). EXPRESS: histone hyperacetylation modulates spinal type II metabotropic glutamate 
receptor alleviating stress-induced visceral hypersensitivity in female rats. Mol. Pain 12:1744806916660722. doi: 10.1177/1744806916660722

Capasso, K. E., Manners, M. T., Quershi, R. A., Tian, Y., Gao, R., Hu, H., et al. (2015). Effect of histone deacetylase inhibitor JNJ-26481585 in pain. J. Mol. Neurosci. 55, 570-578. doi: 10.1007/s12031-014-0391-7

Chen, H. Y., Li, L., and Fu, Z. J. (2014). Histone deacetylase inhibitors trichostatin A and suberoylanilide hydroxamic acid attenuate ventilator-induced lung injury. Pharmazie 69, 55-59.

Chiechio, S. (2016). Modulation of chronic pain by metabotropic glutamate receptors. Adv. Pharmacol. 75, 63-89. doi: 10.1016/bs.apha.2015. 11.001

Chiechio, S., Caricasole, A., Barletta, E., Storto, M., Catania, M. V., Copani, A., et al. (2002). L-Acetylcarnitine induces analgesia by selectively up-regulating mGlu2 metabotropic glutamate receptors. Mol. Pharmacol. 61, 989-996. doi: 10.1124/mol.61.5.989

Chiechio, S., Copani, A., Zammataro, M., Battaglia, G., Gereau, R. W. IV, and Nicoletti, F. (2010). Transcriptional regulation of type-2 metabotropic glutamate receptors: an epigenetic path to novel treatments for chronic pain. Trends Pharmacol. Sci. 31, 153-160. doi: 10.1016/j.tips.2009.12.003

Chiechio, S., and Nicoletti, F. (2012). Metabotropic glutamate receptors, and the control of chronic pain. Curr. Opin. Pharmacol. 12, 28-34. doi: 10.1016/j.coph. 2011.10.010

Chiechio, S., Zammataro, M., Morales, M. E., Busceti, C. L., Drago, F., Gereau, R. W. IV., et al. (2009). Epigenetic modulation of mGlu2 receptors by histone deacetylase inhibitors in the treatment of inflammatory pain. Mol. Pharmacol. 75, 1014-1020. doi: 10.1124/mol.108.054346

Coderre, T. J., and Melzack, R. (1992). The contribution of excitatory amino acids to central sensitization and persistent nociception after formalin-induced tissue injury. J. Neurosci. 12, 3665-3670.

Craft, R. M. (2003). Sex differences in opioid analgesia: “from mouse to man”. Clin. J. Pain 19, 175-186. doi: 10.1097/00002508-200305000-00005

Denk, F., Huang, W., Sidders, B., Bithell, A., Crow, M., Grist, J., et al. (2013). HDAC inhibitors attenuate the development of hypersensitivity in models of neuropathic pain. Pain 154, 1668-1679. doi: 10.1016/j.pain.2013. 05.021

Dharmshaktu, P., Tayal, V., and Kalra, B. S. (2012). Efficacy of antidepressants as analgesics: a review. J. Clin. Pharmacol. 52, 6-17. doi: 10.1177/ 0091270010394852

Erburu, M., Muñoz-Cobo, I., Domínguez-Andrés, J., Beltran, E., Suzuki, T., Mai, A., et al. (2015). Chronic stress and antidepressant induced changes in Hdac5 and Sirt2 affect synaptic plasticity. Eur. Neuropsychopharmacol. 25, 2036-2048. doi: 10.1016/j.euroneuro.2015.08.016

Faillace, M. P., Zwiller, J., and Bernabeu, R. O. (2015). Effects of combined nicotine and fluoxetine treatment on adult hippocampal neurogenesis and conditioned place preference. Neuroscience 300, 104-115. doi: 10.1016/j.neuroscience. 2015. 05.017

Fillingim, R. B., King, C. D., Ribeiro-Dasilva, M. C., Rahim-Williams, B., and Riley, J. L. III. (2009). Sex, gender, and pain: a review of recent clinical and experimental findings. J. Pain 10, 447-485. doi: 10.1016/j.jpain.2008. 12.001

Finnerup, N. B., Attal, N., Haroutounian, S., McNicol, E., Baron, R., Dworkin, R. H., et al. (2015). Pharmacotherapy for neuropathic pain in adults: a systematic review and meta-analysis. Lancet Neurol. 14, 162-173. doi: 10.1016/ S1474-4422(14)70251-0

Finnerup, N. B., Sindrup, S. H., and Jensen, T. S. (2010). The evidence for pharmacological treatment of neuropathic pain. Pain 150, 573-581. doi: $10.1016 /$ j.pain.2010.06.019

Fork, C., Vasconez, A. E., Janetzko, P., Angioni, C., Schreiber, Y., Ferreirós, N., et al. (2017). Epigenetic control of microsomal prostaglandin E synthase-1 by HDAC-mediated recruitment of p300. J. Lipid Res. 58, 386-392. doi: 10.1194/ jlr.M072280

Gilron, I., Jensen, T. S., and Dickenson, A. H. (2013). Combination pharmacotherapy for management of chronic pain: from bench to bedside. Lancet Neurol. 12, 1084-1095. doi: 10.1016/S1474-4422(13)70193-5

Goldenberg, D., Mayskiy, M., Mossey, C., Ruthazer, R., and Schmid, C. (1996). A randomized, double-blind crossover trial of fluoxetine and amitriptyline in the treatment of fibromyalgia. Arthritis Rheum. 39, 1852-1859. doi: 10.1002/ art.1780391111
Gray, V. C., and Hughes, R. N. (2015). Drug-, dose- and sex-dependent effects of chronic fluoxetine, reboxetine and venlafaxine on open-field behavior and spatial memory in rats. Behav. Brain Res. 281, 43-54. doi: 10.1016/j.bbr.2014. 12.023

Grozinger, C. M., and Schreiber, S. L. (2002). Deacetylase enzymes: biological functions and the use of small-molecule inhibitors. Chem. Biol. 9, 3-16. doi: 10.1016/S1074-5521(02)00092-3

Haykal, R. F., and Akiskal, H. S. (1999). The long-term outcome of dysthymia in private practice: clinical features, temperament, and the art of management. J. Clin. Psychiatry 60, 508-518. doi: 10.4088/JCP.v60n0802

Hodes, G. E., Hill-Smith, T. E., Suckow, R. F., Cooper, T. B., and Lucki, I. (2010). Sex-specific effects of chronic fluoxetine treatment on neuroplasticity and pharmacokinetics in mice. J. Pharmacol. Exp. Ther. 332, 266-273. doi: 10.1124/jpet.109.158717

Iyengar, S., Webster, A. A., Hemrick-Luecke, S. K., Xu, J. Y., and Simmons, R. M. (2004). Efficacy of duloxetine, a potent and balanced serotonin-norepinephrine reuptake inhibitor in persistent pain models in rats. J. Pharmacol. Exp. Ther. 311, 576-584. doi: 10.1124/jpet.104.070656

Johnson, M. P., Muhlhauser, M. A., Nisenbaum, E. S., Simmons, R. M., Forster, B. M., Knopp, K. L., et al. (2017). Broad spectrum efficacy with LY2969822, an oral prodrug of metabotropic glutamate $2 / 3$ receptor agonist LY2934747, in rodent pain models. Br. J. Pharmacol. 174, 822-835. doi: 10.1111/bph. 13740

Jones, C. K., Peters, S. C., and Shannon, H. E. (2005). Efficacy of duloxetine, a potent and balanced serotonergic and noradrenergic reuptake inhibitor, in inflammatory and acute pain models in rodents. J. Pharmacol. Exp. Ther. 312, 726-732. doi: 10.1124/jpet.104.075960

Kim, D. K., Hwang, C. K., Wagley, Y., Law, P. Y., Wei, L. N., and Loh, H. H. (2011). p38 mitogen-activated protein kinase and PI3-kinase are involved in up-regulation of mu opioid receptor transcription induced by cycloheximide. J. Neurochem. 116, 1077-1087. doi: 10.1111/j.1471-4159.2010.07 163.x

Kim, S. J., Calejesan, A. A., Li, P., Wei, F., and Zhuo, M. (1999). Sex differences in late behavioral response to subcutaneous formalin injection in mice. Brain Res. 829, 185-189. doi: 10.1016/S0006-8993(99)01353-0

King, J. R., Velasquez, J. C., Torii, M., and Bonnin, A. (2017). Effect of maternal \pm citalopram exposure on P11 expression and neurogenesis in the mouse fetal brain. ACS Chem. Neurosci. 8, 1019-1025. doi: 10.1021/acschemneuro.6b0 0339

Kokras, N., and Dalla, C. (2017). Preclinical sex differences in depression and antidepressant response: implications for clinical research. J. Neurosci. Res. 95, 731-736. doi: 10.1002/jnr.23861

Kornstein, S. G., Schatzberg, A. F., Thase, M. E., Yonkers, K. A., McCullough, J. P., Keitner, G. I., et al. (2000). Gender differences in treatment response to sertraline versus imipramine in chronic depression. Am. J. Psychiatry 157, 1445-1452. doi: 10.1176/appi.ajp.157.9.1445

Kukkar, A., Singh, N., and Jaggi, A. S. (2014). Attenuation of neuropathic pain by sodium butyrate in an experimental model of chronic constriction injury in rats. J. Formos. Med. Assoc. 113, 921-928. doi: 10.1016/j.jfma.2013. 05.013

Kurita, M., Holloway, T., García-Bea, A., Kozlenkov, A., Friedman, A. K., Moreno, J. L., et al. (2012). HDAC2 regulates atypical antipsychotic responses through the modulation of mGlu2 promoter activity. Nat. Neurosci. 15, 1245-1254. doi: $10.1038 / \mathrm{nn} .3181$

Lin, C. R., Cheng, J. K., Wu, C. H., Chen, K. H., and Liu, C. K. (2017). Epigenetic suppression of potassium-chloride co-transporter 2 expression in inflammatory pain induced by complete Freund's adjuvant (CFA). Eur. J. Pain 21, 309-321. doi: 10.1002/ejp.925

Lupu, D., Pop, A., Cherfan, J., Kiss, B., and Loghin, F. (2015). In vitro modulation of estrogen receptor activity by norfluoxetine. Clujul Med. 88, 386-390. doi: $10.15386 /$ cjmed- 476

Mai, A., Massa, S., Rotili, D., Cerbara, I., Valente, S., Pezzi, R., et al. (2005). Histone deacetylation in epigenetics: an attractive target for anticancer therapy. Med. Res. Rev. 25, 261-309. doi: 10.1002/med.20024

Maiarù, M., Morgan, O. B., Tochiki, K. K., Hobbiger, E. J., Rajani, K., Overington, D. W., et al. (2016). Complex regulation of the regulator of synaptic plasticity histone deacetylase 2 in the rodent dorsal horn after peripheral injury. J. Neurochem. 138, 222-232. doi: 10.1111/jnc.13621 
Masuda, T., Nakagawa, S., Boku, S., Nishikawa, H., Takamura, N., Kato, A., et al. (2012). Noradrenaline increases neural precursor cells derived from adult rat dentate gyrus through $\beta 2$ receptor. Prog. Neuropsychopharmacol. Biol. Psychiatry. 36, 44-51. doi: 10.1016/j.pnpbp.2011.08.019

Matsushita, Y., Araki, K., Omotuyi, O. I., Mukae, T., and Ueda, H. (2013). HDAC inhibitors restore C-fibre sensitivity in experimental neuropathic pain model. Br. J. Pharmacol. 170, 991-998. doi: 10.1111/bph.12366

Max, M. B., Lynch, S. A., Muir, J., Shoaf, S. E., Smoller, B., and Dubner, R. (1992). Effects of desipramine, amitriptyline, and fluoxetine on pain in diabetic neuropathy. N. Engl. J. Med. 326, 1250-1256. doi: 10.1056/ NEJM199205073261904

Meneghini, V., Cuccurazzu, B., Bortolotto, V., Ramazzotti, V., Ubezio, F., Tzschentke, T. M., et al. (2014). The noradrenergic component in tapentadol action counteracts $\mu$-opioid receptor-mediated adverse effects on adult neurogenesis. Mol. Pharmacol. 85, 658-670. doi: 10.1124/mol.113.09 1520

Menke, A., and Binder, E. B. (2014). Epigenetic alterations in depression and antidepressant treatment. Dialogues Clin. Neurosci. 16, 395-404.

Menke, A., Klengel, T., and Binder, E. B. (2012). Epigenetics, depression and antidepressant treatment. Curr. Pharm. Des. 18, 5879-5889. doi: 10.2174/ 138161212803523590

Mika, J., Zychowska, M., Makuch, W., Rojewska, E., and Przewlocka, B. (2013). Neuronal and immunological basis of action of antidepressants in chronic pain - clinical and experimental studies. Pharmacol. Rep. 65, 1611-1621. doi: 10.1016/S1734-1140(13)71522-6

Millan, M. J. (2002). Descending control of pain. Prog. Neurobiol. 66, 355-474. doi: 10.1016/S0301-0082(02)00009-6

Mogil, J. S., Wilson, S. G., Chesler, E. J., Rankin, A. L., Nemmani, K. V., Lariviere, W. R., et al. (2003). The melanocortin-1 receptor gene mediates female-specific mechanisms of analgesia in mice and humans. Proc. Natl. Acad. Sci. U.S.A. 100, 4867-4872. doi: 10.1073/pnas.0730053100

Newell-Price, J., Clark, A. J., and King, P. (2000). DNA methylation and silencing of gene expression. Trends Endocrinol. Metab. 11, 142-148. doi: 10.1016/S10432760(00)00248-4

Obata, H., Conklin, D., and Eisenach, J. C. (2005). Spinal noradrenaline transporter inhibition by reboxetine and Xen 2174 reduces tactile hypersensitivity after surgery in rats. Pain 113, 271-276. doi: 10.1016/j.pain.2004. 10.017

Onofrj, M., Ciccocioppo, F., Varanese, S., di Muzio, A., Calvani, M., Chiechio, S., et al. (2013). Acetyl-L-carnitine: from a biological curiosity to a drug for the peripheral nervous system and beyond. Expert Rev. Neurother. 13, 925-936. doi: $10.1586 / 14737175.2013 .814930$

Palazzo, E., Marabese, I., de Novellis, V., Rossi, F., and Maione, S. (2014). Supraspinal metabotropic glutamate receptors: a target for pain relief and beyond. Eur. J. Neurosci. 39, 444-454. doi: 10.1111/ejn.12398

Perisic, T., Zimmermann, N., Kirmeier, T., Asmus, M., Tuorto, F., Uhr, M., et al. (2010). Valproate and amitriptyline exert common and divergent influences on global and gene promoter-specific chromatin modifications in rat primary astrocytes. Neuropsychopharmacology 35, 792-805. doi: 10.1038/npp. 2009

Quitkin, F. M., Stewart, J. W., McGrath, P. J., Taylor, B. P., Tisminetzky, M. S., Petkova, E., et al. (2002). Are there differences between women's and men's antidepressant responses? Am. J. Psychiatry 159, 1848-1854. doi: 10.1176/appi. ajp.159.11.1848

Riley, J. L. III., Robinson, M. E., Wise, E. A., Myers, C. D., and Fillingim, R. B. (1998). Sex differences in the perception of noxious experimental stimuli: a meta-analysis. Pain 74, 181-187. doi: 10.1016/S0304-3959(97)00 199-1

Saarto, T., and Wiffen, P. J. (2005). Antidepressants for neuropathic pain. Cochrane Database Syst. Rev. 20:CD005454. doi: 10.1002/14651858. CD005454

Saarto, T., and Wiffen, P. J. (2007). Antidepressants for neuropathic pain. Cochrane Database Syst. Rev. 17:CD005454. doi: 10.1002/14651858.CD005454. pub2

Sasikumar, T. K., Qiang, L., Burnett, D. A., Greenlee, W. J., Li, C., Grilli, M., et al. (2010). A-ring modifications on the triazafluorenone core structure and their mGluR1 antagonist properties. Bioorg. Med. Chem. Lett. 20, 2474-2477. doi: 10.1016/j.bmcl.2010.03.004
Sharma, N. L., Groselj, B., Hamdy, F. C., and Kiltie, A. E. (2013). The emerging role of histone deacetylase (HDAC) inhibitors in urological cancers. BJU Int. 111, 537-542. doi: 10.1111/j.1464-410X.2012.11647.x

Sindrup, S. H., Bjerre, U., Dejgaard, A., Brøsen, K., Aaes-Jørgensen, T., and Gram, L. F. (1992). The selective serotonin reuptake inhibitor citalopram relieves the symptoms of diabetic neuropathy. Clin. Pharmacol. Ther. 52, 547-552. doi: $10.1038 /$ clpt.1992.183

Sindrup, S. H., Gram, L. F., Brøsen, K., Eshøj, O., and Mogensen, E. F. (1990). The selective serotonin reuptake inhibitor paroxetine is effective in the treatment of diabetic neuropathy symptoms. Pain 42, 135-144. doi: 10.1016/0304-3959(90) 91157-E

Sindrup, S. H., Otto, M., Finnerup, N. B., and Jensen, T. S. (2005). Antidepressants in the treatment of neuropathic pain. Basic Clin. Pharmacol. Toxicol. 96, 399-409. doi: 10.1111/j.1742-7843.2005.pto_ 96696601.x

Singh, V. P., Jain, N. K., and Kulkarni, S. K. (2001). On the antinociceptive effect of fluoxetine, a selective serotonin reuptake inhibitor. Brain Res. 915, 218-226. doi: 10.1016/S0006-8993(01)02854-2

Sorge, R. E., Mapplebeck, J. C., Rosen, S., Beggs, S., Taves, S., Alexander, J. K., et al. (2015). Different immune cells mediate mechanical pain hypersensitivity in male and female mice. Nat. Neurosci. 18, 1081-1083. doi: 10.1038/nn.4053

Sramek, J. J., Murphy, M. F., and Cutler, N. R. (2016). Sex differences in the psychopharmacological treatment of depression. Dialogues Clin. Neurosci. 18, 447-457.

Tao, W., Zhou, W., Wang, Y., Sun, T., Wang, H., Zhang, Z., et al. (2016). Histone deacetylase inhibitor-induced emergence of synaptic $\delta$-opioid receptors and behavioral antinociception in persistent neuropathic pain. Neuroscience 339, 54-63. doi: 10.1016/j.neuroscience.2016.09.015

Tjølsen, A., Berge, O. G., Hunskaar, S., Rosland, J. H., and Hole, K. (1992). The formalin test: an evaluation of the method. Pain 51, 5-17. doi: 10.1016/03043959(92)90003-T

Unruh, A. M. (1996). Gender variations in clinical pain experience. Pain 65, 123-167. doi: 10.1016/0304-3959(95)00214-6

Vierci, G., Pannunzio, B., Bornia, N., and Rossi, F. M. (2016). H3 and H4 lysine acetylation correlates with developmental and experimentally induced adult experience-dependent plasticity in the mouse visual cortex. J. Exp. Neurosci. 10, 49-64. doi: 10.4137/JEN.S39888

Walker, K., Bowes, M., Panesar, M., Davis, A., Gentry, C., Kesingland, A., et al. (2001). Metabotropic glutamate receptor subtype 5 (mGlu5) and nociceptive function. I. Selective blockade of mGlu5 receptors in models of acute, persistent and chronic pain. Neuropharmacology 40, 1-9. doi: 10.1016/S0028-3908(00) 00113-1

Walker, Z., Walker, R. W., Robertson, M. M., and Stansfeld, S. (1998). Antidepressant treatment of chronic tension-type headache: a comparison between fluoxetine and desipramine. Headache 38, 523-528. doi: 10.1046/j. 1526-4610.1998.3807523.x

Wang, Y., Neumann, M., Hansen, K., Hong, S. M., Kim, S., Noble-Haeusslein, L. J., et al. (2011). Fluoxetine increases hippocampal neurogenesis and induces epigenetic factors but does not improve functional recovery after traumatic brain injury. J. Neurotrauma 28, 259-268. doi: 10.1089/neu.2010. 1648

Wolfe, F., Cathey, M. A., and Hawley, D. J. (1994). A double-blind placebo controlled trial of fluoxetine in fibromyalgia. Scand. J. Rheumatol. 23, 255-259. doi: 10.3109/03009749409103725

Wolfe, F., Ross, K., Anderson, J., Russell, I. J., and Hebert, L. (1995). The prevalence and characteristics of fibromyalgia in the general population. Arthritis Rheum. 38, 19-28. doi: 10.1002/art.1780380104

Ximenes, J. C., de Oliveira Gonçalves, D., Siqueira, R. M., Neves, K. R., Santos Cerqueira, G., Correia, A. O., et al. (2013). Valproic acid: an anticonvulsant drug with potent antinociceptive and anti-inflammatory properties. Naunyn Schmiedebergs Arch. Pharmacol. 386, 575-587. doi: 10.1007/s00210-0130853-4

Yang, F., Yang, Y., Wang, Y., Yang, F., Li, C. L., Wang, X. L., et al. (2015). Selective class I histone deacetylase inhibitors suppress persistent spontaneous nociception and thermal hypersensitivity in a rat model of bee venom-induced inflammatory pain. Sheng Li Xue Bao 67, 447-454.

Zammataro, M., Sortino, M. A., Parenti, C., Gereau, R. W. IV., and Chiechio, S. (2014). HDAC and HAT inhibitors differently affect analgesia mediated by 
group II metabotropic glutamate receptors. Mol. Pain 10:68. doi: 10.1186/17448069-10-68

Zhang, Z., Cai, Y. Q., Zou, F., Bie, B., and Pan, Z. Z. (2011). Epigenetic suppression of GAD65 expression mediates persistent pain. Nat. Med. 17, 1448-1455. doi: $10.1038 / \mathrm{nm} .2442$

Zhao, T., Liu, X., Zhen, X., and Guo, S. W. (2011). Levo-tetrahydropalmatine retards the growth of ectopic endometrial implants and alleviates generalized hyperalgesia in experimentally induced endometriosis in rats. Reprod. Sci. 18, 28-45. doi: $10.1177 / 1933719110381928$

Zhao, Z., Fan, L., and Frick, K. M. (2010). Epigenetic alterations regulate estradiol-induced enhancement of memory consolidation. Proc. Natl. Acad. Sci. U.S.A. 107, 5605-5610. doi: 10.1073/pnas.091057 8107

Zhao, Z. Q., Chiechio, S., Sun, Y. G., Zhang, K. H., Zhao, C. S., Scott, M., et al. (2007). Mice lacking central serotonergic neurons show enhanced inflammatory pain and an impaired analgesic response to antidepressant drugs. J. Neurosci. 27, 6045-6053. doi: 10.1523/JNEUROSCI.1623-07. 2007
Zhou, Q. G., Lee, D., Ro, E. J., and Suh, H. (2016). Regional-specific effect of fluoxetine on rapidly dividing progenitors along the dorsoventral axis of the hippocampus. Sci. Rep. 6:35572. doi: 10.1038/srep35572

Zimmermann, N., Zschocke, J., Perisic, T., Yu, S., Holsboer, F., and Rein, T. (2012). Antidepressants inhibit DNA methyltransferase 1 through reducing G9a levels. Biochem. J. 448, 93-102. doi: 10.1042/BJ20120674

Conflict of Interest Statement: The authors declare that the research was conducted in the absence of any commercial or financial relationships that could be construed as a potential conflict of interest.

Copyright (๑) 2017 Zammataro, Merlo, Barresi, Parenti, Hu, Sortino and Chiechio. This is an open-access article distributed under the terms of the Creative Commons Attribution License (CC BY). The use, distribution or reproduction in other forums is permitted, provided the original author(s) or licensor are credited and that the original publication in this journal is cited, in accordance with accepted academic practice. No use, distribution or reproduction is permitted which does not comply with these terms. 